\title{
WET EXPANSION STEAM CYCLES FOR OFFSHORE INDUSTRY
}

\author{
D.P. CLOS, G. SKAUGEN, M. MAZETTI \& D. ROHDE \\ SINTEF Energy Research, Norway.
}

\begin{abstract}
Steam cycles are a mature technology that has been used for many decades to produce power from heat. Novel expanders that can expand in the two-phase region have been developed for years but only recently have achieved a level of maturity that makes them commercially interesting.

In this study wet and dry steam cycles recovering heat from gas turbines in offshore industry are compared in a thermodynamic basis. Three different cycle configurations are studied in three scenarios with different combinations of power and heat demand. Every case is optimized with and without restrictions for two-phase steam expansion.

It is shown that wet expansion cycles can achieve higher steam pressures which increase steam cycle efficiency. Steam cycle power increase has been found to be large for single expansion cases (20\%) due to the low pressures that can be achieved by the dry cycles.

Optimization of two-stage wet expansion does not produce significant improvements and in some cases results are equivalent to single stage wet expansion cycles.

Energy savings and $\mathrm{CO}_{2}$ emissions reduction when comparing with the reference cases without steam cycle installation are found to be in the range of $17 \%-26 \%$.

Keywords: offshore industry, steam cycles, wet expansion.
\end{abstract}

\section{INTRODUCTION}

Gas turbines are used in offshore platforms to provide with electricity needs and to mechanically drive compressors and pumps used in the oil and gas process treatment. Exhaust waste heat can be further used to satisfy heat requirement for different processes in the platforms. As it was shown by Nguyen who performed an exergy analysis for generic oil and gas platforms located in the North Sea, gas turbines account for $60 \%$ of the exergy losses [1].

Introduction of bottoming cycles that can use excess heat from such gas turbines to produce power can improve energy efficiency in offshore platforms and thus help reducing global warming emissions.

Steam cycles are a mature technology that has been used for many decades to generate power in thermal plants. A main concern of those systems is the formation of water droplets during steam expansion, which causes erosion in the turbine blades [2]. In order to avoid that steam must be superheated, which substantially increases the size of the steam generator due to poor heat transfer of water vapour. Moreover, multiple expansion/re-heating stages are commonly employed to increase power output, which further increases system size and complexity. The introduction of steam cycles in offshore industry calls for system simplification and compactness. Several studies have already explored novel combined heat and power configurations including the potential use of $\mathrm{CO}_{2}$ power cycles [3-5].

Recent developments in the field of expanders have produced new designs that not only tolerate formation of water droplets but also allow to directly expand from the two-phase region and even from the liquid saturation point with efficiencies that approach the ones from the conventional cycles [6-15].

Low temperature heat recovery fields such as geothermal and concentrated solar energy industry among others have motivated development of wet expansion devices [6]. The main 
reason behind that is the better thermal matching between working fluid and heat source that can be achieved in the so called 'tri-lateral flash cycle' or TFC, which allows to recover more heat from such sources in a more reversible process than ordinary Rankine cycles.

Development has been ongoing, but only recently have they reached a level of maturity that makes them economically interesting. Two different types of two-phase expanders have emerged, namely the variable phase turbine (VPT) [6-8] and the screw expander [9-15].

Many studies in the literature have compared the use of TFC against traditional organic Rankine cycles (ORC) for low temperature applications but to the best of our knowledge none have been found, which compare the thermodynamic potential between wet expansion high temperature steam cycles and traditional steam cycles. Therefore, the aim in the present study is to assess what advantages could be achieved in terms of improved energy efficiency and/or component size by the use of wet expansion steam cycles in different scenarios of power and heat demand.

\section{METHODOLOGY}

\subsection{Combined heat and power models}

A strategy commonly used to deliver process heat is to circulate a heat transfer fluid such as ethylene glycol or other kinds of thermal oils in secondary loops. This hinders the amount of thermal energy that could be taken by the steam cycle. A way to increase the heat intake by the cycle would be to use the condensing steam out of the steam turbine to deliver the required process heat. In the present study three different combined cycle configurations have been built in Microsoft Excel 2010 using the thermodynamic library Refprop 9 to calculate the cycle state points. A diagram showing the configuration of the different cycles can be seen in Fig. 1.

The first cycle has a single heating and expansion stage for the steam and the heat is delivered by a thermal oil, which recovers the heat left by the steam cycle.

The second cycle has the same configuration as the first one, but in that case the steam is expanded in two stages, allowing for reheating of the steam between them.

Finally, the last cycle, which also has a two stage expansion with reheating of the steam, provides with the heat demand by extracting some of the steam after the first expansion. A condenser is placed at the end to ensure complete condensation of the steam. It should be

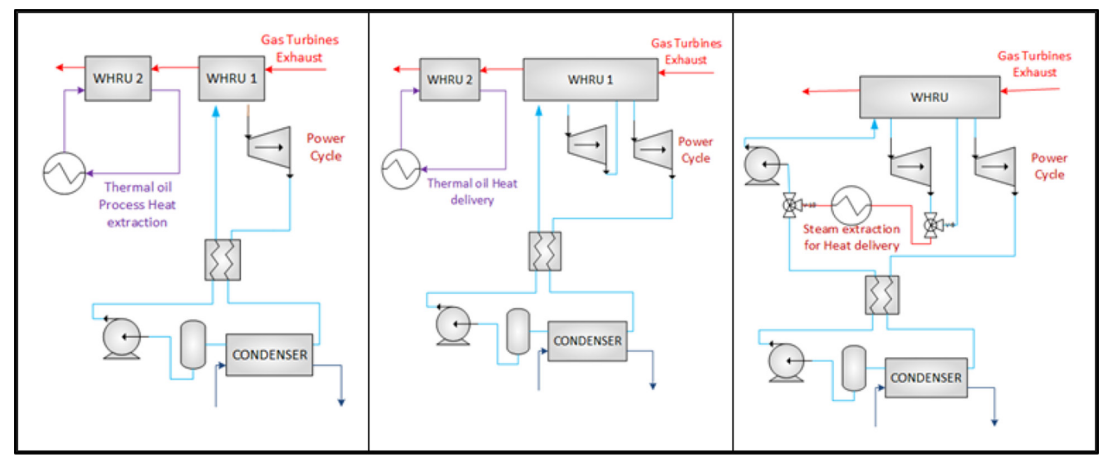

Figure 1: Different steam cycle configurations for power and heat delivery. 
noted that even though the heat uptake from this cycle will be higher than the other cycles its efficiency will be lower due to the potential work loss by the steam extracted.

\subsubsection{Gas turbines}

Gas turbines are built to run optimally at certain design point, usually close to full load. When assessing energy efficiency improvements that would result from installing a bottoming cycle it has to be taken into account that the load of the gas turbine will need to be reduced compared to a base case without bottoming cycle in order to produce the same amount of power. This will result in gas turbines running at lower load and thus lower efficiency, which will reduce the net impact provided by the bottoming cycle.

Another possible scenario when considering the introduction of steam cycles in offshore platforms that have several gas turbines is to remove one of the gas turbines and run the others at higher load together with the steam cycle. This scenario has the highest potential for energy efficiency improvement since it will benefit from waste heat recovery by the steam cycle and gas turbines efficiency increase that arises by running them at higher load.

Gas turbine performance is evaluated with GT MASTER from Thermoflow Inc. [16]. Simulation results with SGT-500 gas turbine are used to generate quadratic correlations to relate the main GT parameters to the gas turbine load as shown in Table 1.

A maximum GT load of $90 \%$ is used as a boundary to have a margin for peak demands.

\subsubsection{Optimization variables}

A list of free variables used in the optimization of the different scenarios studied can be seen in Table 2. In order to solve the non-linear system produced by the combination of those variables the generalized reduced gradient algorithm (GRG) available in Excel is used. The number of sub-problems has been increased for some cases to assess the minimum number to produce global optimum solutions. Results did not seem to improve after 25 sub-problems so that value was used for the calculations together with a convergence factor of 0.001 . Routines in VBA were developed in order to establish reasonable variable boundaries as function of case inputs in order to have a domain broad enough to find global optimum points but narrow enough to ensure results convergence. In all cases net power of the steam cycle has been used as objective function to be maximized. Considering that the increase of steam cycle net power supposes a reduction of gas turbines load and thus fuel consumption for a given power and heat demand this supposes a maximum in overall process efficiency as well.

Table 1: SGT500 gas turbine main parameters as function of GT load.

\begin{tabular}{lllllll}
\hline Function & \multicolumn{7}{c}{ Values } \\
\hline GT load & $100 \%$ & $90 \%$ & $80 \%$ & $70 \%$ & $60 \%$ & $50 \%$ \\
GT power output (MW) & 16.5 & 14.9 & 13.2 & 11.6 & 10.0 & 8.3 \\
Exhaust mass flow (kg/s) & 92.5 & 88.7 & 84.8 & 80.8 & 76.9 & 72.8 \\
Temperature $\left({ }^{\circ} \mathrm{C}\right)$ & 377 & 365 & 352 & 340 & 327 & 313 \\
$\mathrm{CO}_{2}$ concentration exhaust & $2.1 \%$ & $2.0 \%$ & $1.9 \%$ & $1.8 \%$ & $1.7 \%$ & $1.6 \%$ \\
$($ mole $\%)$ & & & & & & \\
\hline
\end{tabular}


Table 2: Optimization variables for the combined cycles.

\begin{tabular}{llll}
\hline VARIABLES & Cycle 1 & Cycle 2 & Cycle 3 \\
\hline Mass Flow steam & $\times$ & $\times$ & $\times$ \\
Steam low pressure & $\times$ & $\times$ & $\times$ \\
Steam intermediate pressure & & $\times$ & $\times$ \\
Steam high pressure & $\times$ & $\times$ & $\times$ \\
Gas turbines load & $\times$ & & $\times$ \\
Steam mass flow for heat delivery & & $\times$ & $\times$ \\
Outlet temperature GT exhaust 1 & $\times$ & $\times$ & $\times$ \\
Outlet temperature GT exhaust 2 & & $\times$ & $\times$ \\
Outlet temperature water sink & $\times$ & $\times$ & $\times$ \\
\hline
\end{tabular}

\section{INPUTS AND ASSUMPTIONS}

A list with the main parameters used in the models can be seen in Table 3. Minimum and maximum steam pressures have been limited to 0.005 bar and 50 bar, respectively. Exhaust minimum temperature has been set to $150^{\circ} \mathrm{C}$ as a conservative value to avoid condensation of corrosive acids. Moreover cycle heat losses and steam pressure drops have been neglected for simplicity.

Isentropic efficiencies for pumps and expanders have been kept at the same constant value for both dry and wet cases. This allows for a direct and purely thermodynamic comparison between both scenarios considering that further development of wet expanders will achieve similar efficiency levels.

The percentage of steam vaporization before and after expansion in the steam turbine has been controlled through inequality constraints calculated using eqs (1) and (2). Enthalpy values relative to the saturation lines at high and low pressure for values before and after expansion, respectively, are used as a measure of steam quality to be able to compute them outside the two-phase envelope. That means that negative values for vaporization are obtained for liquid enthalpies (below $0 \%$ vaporization) and values above $100 \%$ are obtained for superheated vapour enthalpies. Values for dry expansion were set to a minimum of $100 \%$ steam vaporization before expansion and $95 \%$ vaporization after expansion since real systems do have a certain degree of condensation at the outlet of the steam turbine. On the other hand the minimum vaporization value for wet expansion cases was set to zero to allow expansion for ranges from liquid saturation point to partial vaporization and superheat.

$$
\begin{gathered}
\text { Vaporization before expansion }=\frac{\left(\mathrm{H}_{\text {bef exp }}-H_{\text {sat liq } \mathrm{HP}}\right)}{\left(H_{\text {sat vap HP }}-H_{\text {sat liq HP }}\right)} \\
\text { Vaporization after expansion }=\frac{\left(\mathrm{H}_{\text {aft exp }}-\mathrm{H}_{\text {sat liq LP }}\right)}{\left(\mathrm{H}_{\text {sat vap LP }}-\mathrm{H}_{\text {sat liq LP }}\right)}
\end{gathered}
$$

Power produced has been calculated as a sum of gas turbines and steam cycle's net power and set as an equality constraint to satisfy power demand. 
Heat demand was calculated using eqn (3) for the cycles using thermal oil by calculating the heat left between the exhaust after transfer to the steam cycle and the minimum temperature for exhaust cooling. For the steam extraction case eqn (4) was used which calculates the final enthalpy of the steam to satisfy the heat demand constraint.

$$
\begin{gathered}
\text { Heat produced oil }=M F_{\text {exhaust }} \times C_{p} \times\left(T_{\text {exh out WHRU }}-T_{\text {exhMin }}\right) \\
\text { Heat produced steam extraction }=M F_{\text {Steam }} \times\left(H_{\text {aft exp }}-H_{\text {needed }}\right)
\end{gathered}
$$

Estimation of heat transfer areas for the waste heat recovery unit (WHRU) and condenser have been performed by dividing the heat exchangers in 20 parts and using eqn (5) with different heat transfer coefficients estimated depending on the heat transfer region as can be seen in Table 3. U values for the WHRU are constrained to a large degree by the low heat transfer value from the dirty flue gas side.

Table 3: Cycle and process parameters.

\begin{tabular}{ll}
\hline Parameter type & Value \\
\hline Cycle inputs & \\
High pressure max (bar) & 50 \\
low pressure min (bar) & 0.005 \\
eff expander $(\%)$ & 80 \\
eff pump $(\%)$ & 70 \\
Generator efficiency & 97 \\
T water in condenser $\left({ }^{\circ} \mathrm{C}\right)$ & 15 \\
U WHRU pre/boil $\left(\mathrm{W} / \mathrm{m}^{2} / \mathrm{K}\right)$ & 60 \\
U WHRU superheat $\left(\mathrm{W} / \mathrm{m}^{2} / \mathrm{K}\right)$ & 40 \\
$\mathrm{U}$ condenser desuperheat $\left(\mathrm{W} / \mathrm{m}^{2} / \mathrm{K}\right)$ & 300 \\
$\mathrm{U}$ condenstation $\left(\mathrm{W} / \mathrm{m}^{2} / \mathrm{K}\right)$ & 1000 \\
Process inputs & \\
Min temperature exhaust $\mathrm{GTs}\left({ }^{\circ} \mathrm{C}\right)$ & 150 \\
Min pinch WHRU exhaust $/ \mathrm{Hot}$ hoil $\left({ }^{\circ} \mathrm{C}\right)$ & 10 \\
LHV fuel GTs $(\mathrm{methane}, \mathrm{kJ} / \mathrm{kg})$ & 50000 \\
Constraints & Set by case \\
Power demand & 100 \\
Heat demand & 10 \\
Min temperature heat demand $\left({ }^{\circ} \mathrm{C}\right)$ & 5 \\
Pinch WHRU $\left({ }^{\circ} \mathrm{C}\right)$ & Dry $/ \mathrm{Wet}$ \\
Pinch condenser $\left({ }^{\circ} \mathrm{C}\right)$ & \\
Vaporization out WHRU $(\%)$ & Vy case \\
Vaporization out steam turbine $(\%)$ & \\
\hline & \\
&
\end{tabular}


Table 4: Energy demand for the different case studies.

\begin{tabular}{lll}
\hline Case & Power demand (MW) & Heat demand (MW) \\
\hline 1 & 50 & 25 \\
2 & 50 & 5 \\
3 & 50 & 0 \\
\hline
\end{tabular}

$$
A=\frac{Q}{U \times L M T D}
$$

\subsection{Case studies}

In order to assess the potential energy savings that can be achieved by using steam cycles in offshore oil and gas platforms three case scenarios based on different combination of power and heat demand have been considered and are displayed in Table 4.

Energy consumption for base cases (without steam cycle) for each case were set by calculating the minimum number of turbines and their average load to provide with power and heat demand.

It has been considered that each gas turbine has a WHRU installed. Steam generated in the different WHRU is then gathered and sent to the steam turbine (same temperature and pressure levels are considered for simplicity).

The possibility of removing a gas turbine and running the rest at higher load with a steam cycle has been introduced. If power or heat demand cannot be satisfied the number of GTs are kept running at a lower load to account for the power produced by the steam cycle.

Estimation of the overall process efficiency was performed by using eqn (6) which considers the amount of fuel used to supply power and heat demands.

$$
\text { Overall efficiency }=\frac{\text { Energy demand }(\text { power and heat })}{\text { Energy consumption }(\text { Fuel spent } * \text { LHV })}
$$

\section{RESULTS AND DISCUSSION}

Results for the different case studies can be seen in Tables 5-7. Since the power demand is the same for all of them the same number of gas turbines and mean load is required. First law efficiency however is reduced for cases with lower or none heat demand ( 2 and 3, respectively) since less of the waste heat generated by the gas turbines is used.

\subsection{Case 1: Large heat demand (50\% power demand)}

Results for the first case scenario can be seen in Table 5. For the case of cycle 1 with a single heating and expansion stage the increase in net power when expanding to the two phase region is rather large (21\%). The optimum point is found at $83 \%$ of vaporization at the outlet of the steam turbine. The reason for this better performance is the fact that the wet case can achieve the maximum allowed pressure of 50 bar compared to the 2.4 bar for the dry case. This increases the thermal efficiency of the steam cycle from $23 \%$ to $30 \%$ and supposes a reduction in fuel consumption and thus $\mathrm{CO}_{2}$ emissions of $13.5 \%$. The overall increase on 
plant efficiency is $3 \%$. The counter effect of the increased power output is the concomitant increase in surface area for the WHRU, which is doubled for cycle 1.

On the other hand wet expansion cycles 2 and 3 do not show a noticeable increase in net power when compared to the dry cases. This is due to the higher pressures attainable by the dry cycles with reheating configuration as can be seen in Fig. 2, where the T-H diagrams for the different optimized cycles are displayed.

It is interesting to notice that cycles 2 and 1 produce the same results for the wet expansion case, which means that there is no thermodynamic advantage of having a two-stage expansion cycle instead of a single-stage one if wet expanders are used.

Table 5: Case 1 (large heat demand) overall results for the different cycles for both dry and wet cases.

\begin{tabular}{|c|c|c|c|c|c|c|c|}
\hline \multirow[t]{2}{*}{ Case 1} & \multirow[t]{2}{*}{$\begin{array}{l}\text { Base } \\
\text { case }\end{array}$} & \multicolumn{2}{|c|}{ Cycle 1} & \multicolumn{3}{|c|}{ Cycle 2} & \multirow{2}{*}{$\frac{\text { Cycle } 3}{\text { Wet }}$} \\
\hline & & Dry & Wet & Dry & Wet & Dry & \\
\hline Number turbines & 4 & 3 & 3 & 3 & 3 & 3 & 3 \\
\hline turbines load & $76 \%$ & $86 \%$ & $83 \%$ & $83 \%$ & $83 \%$ & $82 \%$ & $82 \%$ \\
\hline net power (MW) & & 7.3 & 8.8 & 9.0 & 9.0 & 9.4 & 9.5 \\
\hline $\begin{array}{l}\text { Steam cycle } \\
\text { efficiency }\end{array}$ & & $23 \%$ & $30 \%$ & $30 \%$ & $30 \%$ & $17 \%$ & $18 \%$ \\
\hline Overall efficiency & $46 \%$ & $59 \%$ & $60 \%$ & $61 \%$ & $61 \%$ & $61 \%$ & $61 \%$ \\
\hline MF wf $(\mathrm{kg} / \mathrm{s})$ & & 10.3 & 10.1 & 8.7 & 10.0 & 17.6 & 17.7 \\
\hline wf HP (bar) & & 6.6 & 50.0 & 50.0 & 50.0 & 10.1 & 10.2 \\
\hline wf IP(bar) & & & & 5.7 & 2.0 & 1.0 & 1.0 \\
\hline wf LP (bar) & & 0.03 & 0.03 & 0.03 & 0.03 & 0.03 & 0.03 \\
\hline $\mathrm{T}$ gas out $\left({ }^{\circ} \mathrm{C}\right)$ & & 242.9 & 244.2 & 244.3 & 244.3 & 150.0 & 150.0 \\
\hline $\begin{array}{l}\text { Fuel saved } \\
\text { (thousand t/a) }\end{array}$ & & 18 & 21 & 21 & 21 & 22 & 22 \\
\hline $\begin{array}{l}\mathrm{CO}_{2} \text { saved } \\
\text { (thousand } \mathrm{t} / \mathrm{a} \text { ) }\end{array}$ & & 53 & 60 & 60 & 61 & 63 & 63 \\
\hline $\begin{array}{l}\text { Percentage of } \\
\text { energy savings }\end{array}$ & & $17 \%$ & $19 \%$ & $20 \%$ & $20 \%$ & $20 \%$ & $20 \%$ \\
\hline A WHRU $\left(\mathrm{m}^{2}\right)$ & & 4992 & 10298 & 11847 & 10247 & 21595 & 22072 \\
\hline A condenser $\left(\mathrm{m}^{2}\right)$ & & 3048 & 3073 & 3042 & 3032 & 2449 & 2324 \\
\hline 1 st exp vap $\%$ & & $95 \%$ & $83 \%$ & $96 \%$ & $93 \%$ & $102 \%$ & $103 \%$ \\
\hline 2 nd exp vap $\%$ & & & & $95 \%$ & $82 \%$ & $95 \%$ & $91 \%$ \\
\hline
\end{tabular}


Table 6: Case 2 (low heat demand) overall results for the different cycles for both dry and wet cases.

\begin{tabular}{|c|c|c|c|c|c|c|c|}
\hline \multirow[t]{2}{*}{ Case 2} & \multirow[t]{2}{*}{ Base case } & \multicolumn{2}{|c|}{ Cycle 1} & \multicolumn{2}{|c|}{ Cycle 2} & \multicolumn{2}{|c|}{ Cycle 3} \\
\hline & & Dry & Wet & Dry & Wet & Dry & Wet \\
\hline Number turbines & 4 & 3 & 3 & 3 & 3 & 3 & 3 \\
\hline turbines load & $75.5 \%$ & $79 \%$ & $76 \%$ & $76 \%$ & $76 \%$ & $76 \%$ & $76 \%$ \\
\hline net power (MW) & & 10.8 & 12.3 & 12.1 & 12.5 & 12.1 & 12.3 \\
\hline Steam cycle efficiency & & $23 \%$ & $27 \%$ & $26 \%$ & $27 \%$ & $24 \%$ & $24 \%$ \\
\hline Overall efficiency & $34.0 \%$ & $46 \%$ & $47 \%$ & $47 \%$ & $48 \%$ & $47 \%$ & $47 \%$ \\
\hline $\begin{array}{l}\text { Percentage of energy } \\
\text { savings }\end{array}$ & & $22 \%$ & $25 \%$ & $24 \%$ & $25 \%$ & $24 \%$ & $25 \%$ \\
\hline 1 st exp vap $\%$ & & $95 \%$ & $88 \%$ & $95 \%$ & $106 \%$ & $101 \%$ & $101 \%$ \\
\hline 2nd exp vap $\%$ & & & & $95 \%$ & $88 \%$ & $95 \%$ & $90 \%$ \\
\hline
\end{tabular}

Table 7: Case 3 (no heat demand) overall results for the different cycles for both dry and wet cases.

\begin{tabular}{llllll}
\hline Case 3 & Base case & Cycle 1 & \multicolumn{3}{l}{ Cycle 2/3 } \\
\hline & & Dry & Wet & Dry & Wet \\
\hline Number turbines & 4 & 3 & 3 & 3 & 3 \\
turbines load & $75.5 \%$ & $77 \%$ & $75 \%$ & $75 \%$ & $74 \%$ \\
& & & & & \\
net power (MW) & & 11.6 & 12.9 & 12.9 & 13.1 \\
Steam cycle eff (\%) & & $23 \%$ & $26 \%$ & $26 \%$ & $26 \%$ \\
Overall eff (\%) & $30.9 \%$ & $43 \%$ & $44 \%$ & $44 \%$ & $44 \%$ \\
Energy savings (\%) & & $24 \%$ & $26 \%$ & $26 \%$ & $26 \%$ \\
1st exp vap \% & & $95 \%$ & $51 \%$ & $109 \%$ & $49 \%$ \\
2nd exp vap \% & & & & $95 \%$ & $50 \%$ \\
\hline
\end{tabular}

Finally, cycle 3 with steam extraction for process heat delivery produces $5 \%$ more power than cycle 2, which uses thermal oil. This small advantage would diminish for higher heat demand temperatures since the potential work loss by the steam extracted would be greater at larger temperatures and thus pressures. Given the present restrictions of $150^{\circ} \mathrm{C}$ minimum exhaust temperature, the other cycles would not be penalized for heat demand temperatures increase for values below $150^{\circ} \mathrm{C}$ since the heat taken by the thermal oil will be above this temperature. 


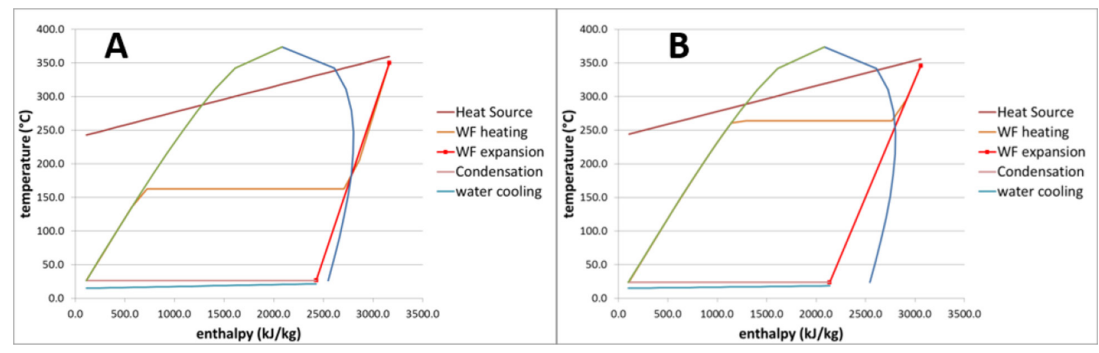

Figure 2: Optimized results for case 1 (large heat demand) for the cycles 1 dry case (A) and wet case (B), cycles 2 dry case (C) and wet case (D), cycles 3 dry case (E) and wet case $(\mathrm{F})$.

\subsection{Case 2: Intermediate heat demand (10\% of power demand)}

Results for case 2, which can be seen in Table 6, are rather analogous to the first case but energy efficiency increase for the wet cases is slightly lower. This is due to the larger penalty in maximum achievable steam pressure that the wet cases undergo due to the fact that the exhaust can be cooled down to a larger degree than case 1 . In this case the maximum steam pressure, which is reached by cycle 2 is only 20.1 bar out of the maximum allowed pressure of 50 bar. In this case steam extraction (cycle 3 ) does not improve results from cycle 2 (thermal oil). Percentages of energy savings are greater than case one due to the lower waste heat utilization of the base case.

\subsection{Case 3: No heat demand}

The last scenario without heat demand can be seen in Table 7. In that case the optimized wet expansion cycles have a partially vaporized fluid at the inlet of the steam turbine as opposed to the previous scenarios were the steam was fully evaporated and superheated to meet the pinch constraint. This can be seen in Fig. 3 where T-H diagrams for the optimized cycles are

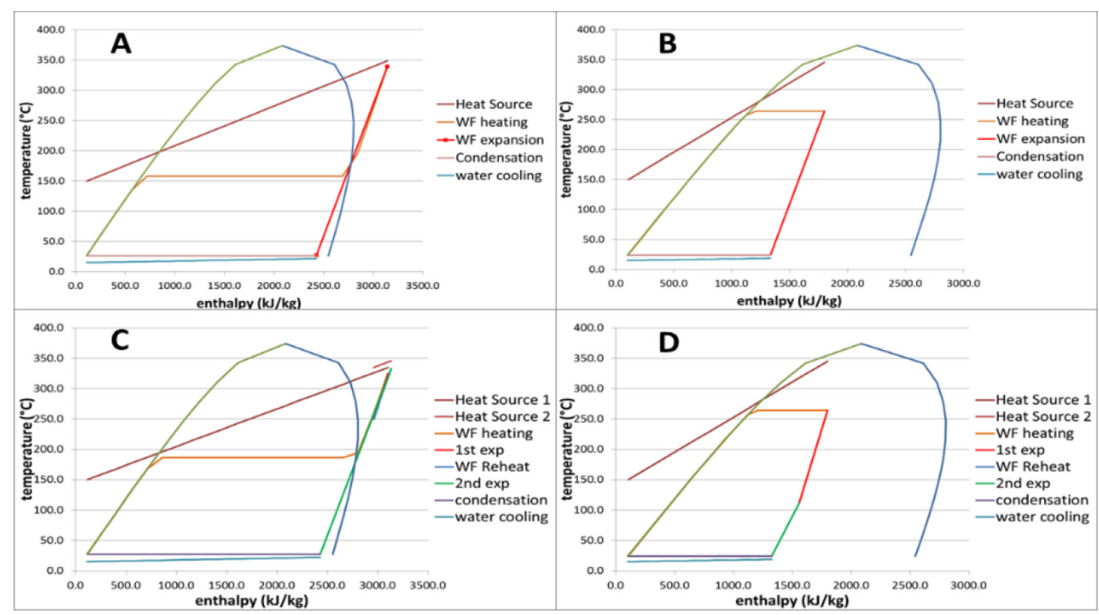

Figure 3: Optimized results for case 3 (no heat demand) for the cycles 1 dry case (A) and wet case (B), cycles 2 dry case (C) and wet case (D). 
displayed. Energy efficiency improvement is in the same line as the previous cases with only cycle 1 with single stage expansion having a better performance (10.5\% higher net power). In that case cycles 2 and 3 are equivalent since they only differ in the heat demand delivery which is set to zero.

\section{CONCLUSIONS}

Wet expansion has shown good potential for single-stage expansion cycles by allowing steam cycles to reach higher pressures than the dry cases. A maximum increase of net power output $(20.8 \%)$ has been found for the case with large heat demand by expansion from superheated vapour to $83 \%$ vaporized steam. Heat transfer areas for the WHRUs were increased by around $100 \%$ for these cases.

No substantial benefits were obtained when using wet expansion in two-stage expansion cycles which have produced equivalent results than the single-stage wet expansion cases. The second scenario with intermediate amount of heat demand produced analogous results than the first one. Finally the optimum wet cases for the third scenario without heat demand were found to have partial steam vaporization before entering the steam turbine with steam qualities around $50 \%$ at the outlet of the expander.

Overall energy efficiency was increased by 13 to 15 percentage points compared with the reference case without steam cycle. Maximum overall efficiency has been found to be $61 \%$ for the case with larger heat demand and down to $47 \%$ for the case with no heat demand with potential for $\mathrm{CO}_{2}$ savings between 53 and 79 thousand tonnes per year.

From offshore installations perspective the thermodynamic improvement found for single-stage wet expansion cycles is quite attractive due to the simplicity and compactness of such a layout. However, implementation of novel expanders will require further assessment on final effect on components size and weight and other general technical considerations.

\section{ACKNOWLEDGEMENTS}

The author(s) acknowledge the partners: ENGIE E\&P Norge AS, Alfa Laval, Statoil, Marine Aluminium, NTNU and the Research Council of Norway, strategic Norwegian research program PETROMAKS2 (\# 233947) for their support.

\section{REFERENCES}

[1] Nguyen, T-V., Pierobon, L., Elmegaard, B., Haglind, F., Breuhaus, P. \& Voldsund, M., Exergetic assessment of energy systems on North Sea oil and gas platforms. Energy, 62, pp. 23-26, 2013. http://dx.doi.org/10.1016/j.energy.2013.03.011

[2] Kehlhofer, R.H., Warner, J., Nielsen, H. \& Bachman, R., Combined-Cycle Gas and Steam Turbine Power Plants, PennWell Publishing Company, 1999.

[3] Mazzetti, M.J, Nekså, P., Walnum, H.T. \& Hemmingsen, A.K.T., Energy-efficient technologies for reduction of offshore $\mathrm{CO}_{2}$ emissions. Oil and Gas Facilities, 3(01), pp. 40-47, 2014. http://dx.doi.org/10.2118/169811-PA

[4] Mazzetti, M., Kus, B., Walnum, H., Nekså, P., Skaugen, G., Hagen, B. \& Ladam, Y., Flexible combined heat and power systems for offshore oil and gas facilities with $\mathrm{CO}_{2}$ bottoming cycles. Proceedings of the ASME Power Conference, 2, 2014. 
[5] Skaugen, G., Walnum, H.T., Hagen, B., Kus, B., Clos, D., Mazzetti, M. \& Nekså, P., Design and optimization of waste heat recovery unit using carbon dioxide as cooling fluid. Proceedings of the ASME Power Conference, 2, 2014. http://dx.doi.org/10.1115/power2014-32165

[6] Welch, P., Boyle, P., Sells, M. \& Murillo, I., Performance of new turbines for geothermal power plants. Geothermal Resources Council Transactions, 34, pp. 1091-1096, 2010.

[7] Welch, P. \& Boyle, P., New turbines to enable efficient geothermal power plants. Geothermal Resources Council Transactions, 33, pp. 765-772, 2009.

[8] Welch, P., Boyle, P., Giron, M. \& Sells, M., Construction and startup of low temperature geothermal power plants. Geothermal Resources Council Transactions, 35, pp. 1351-1356, 2011.

[9] Öhman, H. \& Lundqvist, P., Comparison and analysis of performance using low temperature power cycles. Applied Thermal Engineering, 52(1), pp. 160-169, 2013. http://dx.doi.org/10.1016/j.applthermaleng.2012.11.024

[10] Smith, I.K., Stosic, N. \& Kovacevic, A., Screw expanders increase output and decrease the cost of geothermal binary power plant systems. Geothermal Resources Council Transactions, 29, pp. 787-794, 2005.

[11] Smith, I.K., Stosic, N. \& kovacevic, A., Power recovery from low cost two-phase expanders. Geothermal Resources Council Transactions, 25, pp. 601-605, 2001.

[12] Conference, Purdue University, Indiana, USA.

[13] Smith, I., Stosic, N. \& Aldis, C., Trilateral flash cycle system: a high efficiency power plant for liquid resources. World Geothermal Congress, Florence: Italy, 1995.

[14] http://www.opcon.se/web/Opcon_Powerbox_WST-CU_2.aspx

[15] Thermoflow. GT MASTER 21.0; 2011. 